\title{
Implementasi Face Recognition Untuk Mengakses Ruangan
}

\author{
Alwan Suryansah ${ }^{1}$, Roni Habibi ${ }^{2}$, Rolly Maulana Awangga ${ }^{3}$, Rd. Nuraini Siti Fatonah ${ }^{4}$ \\ Politeknik Pos Indonesia \\ ${ }^{1}$ alwansuryansah1 egmail.com \\ ${ }^{2}$ ronihabibilpoltekpos.ac.id \\ 3 awangga@poltekpos.ac.id \\ ${ }^{4}$ nurainiepoltekpos.ac.id
}

\begin{abstract}
Abstrak - Teknologi biometrik yang berkembang saat ini seperti pengenalan sidik jari, pengenalan retina mata dan sebagainnya mengharuskan seseorang memposisikan tubuh pada posisi yang sesuai dengan posisi kamera yang membuat teknologi ini terkesan kaku, untuk itu sebuah sistem identifikasi lebih fleksibel dan bersifat otomatis dapat mencegah pencurian. Pada penelitian ini dirancang sebuah sistem keamanan yang dapat mengakses pintu masuk menggunakan face recognition berbasis Arduino Uno. Salah satu solusi keamanan dalam melakukan ototentikasi adalah menggunakan bagian tubuh manusia yaitu wajah. Sistem dapat mendeteksi objek wajah sebagai citra dari kamera. Setelah objek terdeteksi, sistem akan melakukan pencocokan wajah dengan citra wajah yang terdapat pada database sistem. Citra akan diproses dengan menggunakan metode LBPH. Sistem ini merupakan penerapan Smart Gate dalam sistem keamanan dengan tujuan dapat mengamankan ruangan yang bersifat pribadi/ private dengan menggunakan biometric fece recognition, penggunaan komponenkomponen elektronik dapat digunakan sebagai alat yang dapat mengenal karakter wajah agar dapat mengakses ruangan, dan dapat mengimplementasikan algoritma LBPH dalam pengenalan karakter wajah pada sistem yang akan di bangun. Hasil dari penelitian ini adalah kendali privilege pada Smart Gate menggunakan Arduino Uno dan biometric face recognition dapat meningkatkan keamanan pada ruangan, dapat memaksimalkan penggunaan komponen-komponen elektronik dan dapat mengimplementasikan algoritma LBPH.
\end{abstract}

Kata kunci: Face Recognition, LBPH, Arduino Uno.

\section{Pendahuluan}

Pengembangan teknik pengenalan wajah atau face recognition cukup sulit karena wajah manusia sangat kompleks, multidimensi, dan sering berubah sesuai dengan perubahan lingkungan dan situasi. Oleh karena itu, pembuatan sistem otomatis pengenalan wajah dan atau ekspresi wajah merupakan tantangan bagi para ahli sampai dengan saat ini. Biometrics merupakan teknologi pengenalan diri dengan menggunakan bagian tubuh atau perilaku manusia. Contohnya yaitu dengan pengenalan sidik jari, retina, iris, pola dari wajah [1]. Salah satu ciri biometric yang paling banyak digunakan dalam penelitianpenelitian selama ini adalah ciri wajah (face) seperti untuk face detection dan face recognition [2].

Semakin tingginya angka kriminalitas dan pembobolan yang terjadi saat ini, menyebabkan sistem keamanan menjadi kebutuhan yang mutlak untuk diterapkan, untuk itu dibutuhkan suatu perangkat sistem keamanan yang dapat menjaga full time untuk melindungi aset dan privasi yang dimiliki. Sehingga diharapkan dengan aplikasi sistem keamanan tersebut dapat memberikan rasa aman dan nyaman, selain hal tersebut tentunya dengan aplikasi sistem keamanan maka dapat menekan angka kriminalitas yang terjadi di masyarakat baik pencurian maupun kejahatan yang lain [3].

Pintu menjadi hal yang paling penting dalam sistem keamanan rumah, perusahaan, dan kantor-kantor pemerintah, dan gedung-gedung penting lainya hal ini karena fungsi pintu sebagai akses utama untuk masuk. Adanya pemasangan sistem keamanan pada pintu tersebut merupakan suatu bentuk otomatisasi sebagai dampak positif dari perkembangan teknologi. Dengan otomatisasi tersebut maka peran manusia akan digantikan oleh suatu alat atau mesin, karena pada dasarnya pintu gerbang akan terbuka sendiri jika password yang dimasukkan benar sehingga diharapkan nantinya setiap pintu tidak harus dijaga terusmenerus oleh manusia karena sistem ini juga telah dilengkapi dengan alarm yang akan berbunyi jika pintu dibuka secara paksa, sistem cerdas yang akan dibangun dalam penelitian ini adalah dengan menggunakan Algoritma LBPH. [3]. Untuk meningkatkan keamanan pada ruangan dan memberikan hak akses. Hasil yang ditunjukan pada penelitian ini adalah untuk mengamankan ruangan yang bersifat pribadi/ private, Untuk komponenkomponen elektronik untuk menggunakan suatu alat yang dapat mengenal karakter wajah agar dapat mengakses ruangan. Dan untuk mengimplementasikan algoritma $L B P H$ untuk pengenalan karakter wajah pada sistem yang akan di bangun.

\section{METODE PENELITIAN}

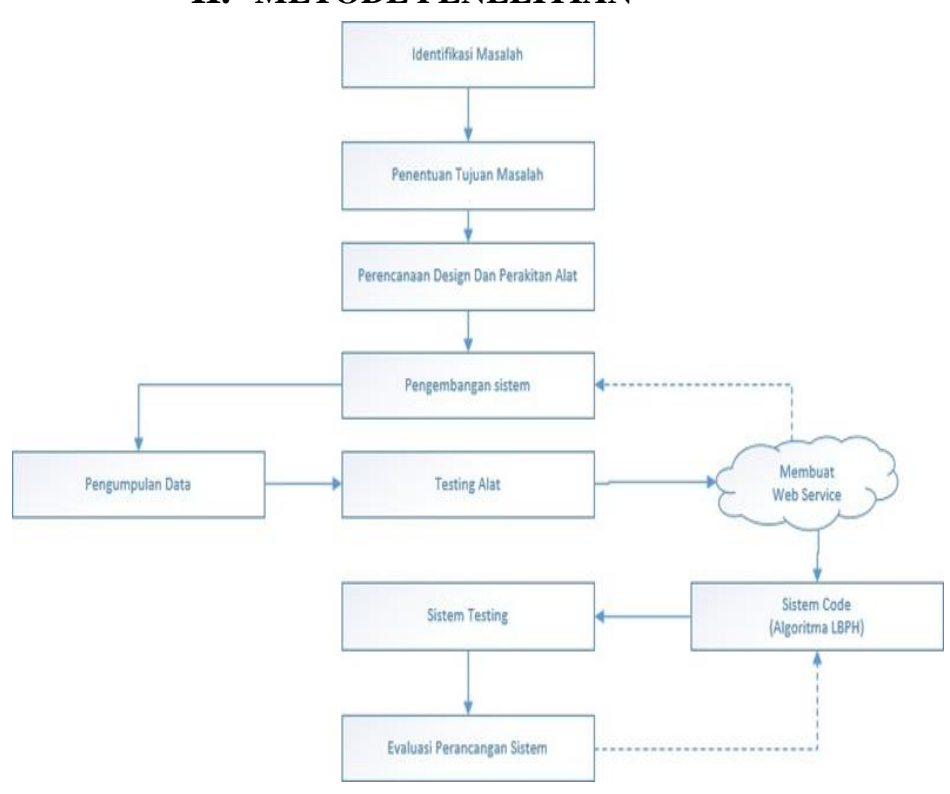

Gambar 1. Metodelogi Penelitian

Tahapan-tahapan Diagram Alur Metodologi

1. Identifikasi Masalah

Pada penelitian ini, peneliti akan membahas mengenai implementasi face recognition untuk mengakases Ruangan, 
bagimanah mengamankan ruangan yang bersifat pribadi/ private dengan menggunakan pengembangan biometrik face recognition, bagaimana mengintegrasikan komponen-komponen elektronik untuk menggunakan suatu alat yang dapat mengenal karakter wajah agar dapat mengakses ruangan dan bagimanah mengimplementasikan algoritma lbph untuk pengenalan karakter wajah pada sistem yang akan di bangun .

2. Penentuan Tujuan Masalah

Adapun tujuan dilaksanankannya untuk mengamankan ruangan yang bersifat pribadi/private dengan menggunakan biometric face recognition, penggunaan komponen-komponen elektronik untuk menggunakan suatu alat yang dapat mengenal karakter wajah agar dapat mengakses ruangan dan untuk mengimplementasikan algoritma LBPH untuk pengenalan karakter wajah pada sistem yang akan di bangun

3. Perencanaan Desain dan Perakitan Alat

Pada tahap ini peneliti akan melakukan identifikasi apa saja yang dibutuhkan dalam perancangan sistem pada smart gate menggunakan biometric face recognition. Perancangan sistem dibuat untuk memberikan gambaran kepada pengguna berdasarkan biometric face recognition yang digunakan. Perancangan design dan perakitan alat juga dibuat untuk mengumpulkan data yang dibutuhkan dalam melakukan kendali privilege pada smart gate berbasis mikrokontroler.

4. Pengembangan Sistem

Pada tahap ini peneliti melakukan pengembangan sistem dengan beberapa percobaan penelitian terhadap beberapa biometric face recognition dan yang telah didaftarkan sebelumnya untuk memastikan bahwa kendali privilege yang dibangun berjalan dengan baik atau tidak. Pengembangan sistem dilakukan dengan melakukan pengumpulan data, dimana dari data tersebut akan dilakukan pengetesan alat pada proses testing alat untuk melakukan evaluasi pada perancangan alat dibangun webservice sebagai pendukung proses berjalannya sistem.

5. Pengkodean Sistem

Pada tahap ini peneliti akan melakukan pengkodean sistem berdasarkan proses webservice yang sudah berjalan ke dalam bahasa pemograman untuk membangun sistem. Pengkodean tersebut dilakukan dengan menerapkan Algoritma $L B P H$ untuk melakukan pengelompokan hak akses pada kendali privilege pada smart gate yang berbasis mikrokontroler.

6. Pengujuan Sistem

Langkah selanjutnya pengujian sistem dimana peneliti akan melakukan prosedur pengujian secara keseluruhan, di ikuti dengan analisis kerentanan resiko. Resiko yang di maksud adalah suatu kondisi yang memiliki kerentanan kritis yang mempunyai prioritas tinggi kemudian di ikuti dengan urutan yang lebih rendah sehingga sistem yang dibuat dapat diperbaiki untuk meminimalisir kesalahan yang dilakukan

7. Evaluasi Perencanaan Sistem

Pada tahap ini peneliti akan mendapatkan hasil evaluasi dari sistem yang sudah dibangun berdasarkan alat dari smart gate yang menggunakan biometric face recognition. Apakah sistem yang telah dibangun tersebut telah sesuai dengan latar belakang masalah pada penelitian yang dilakukan. Jika sistem yang dibangun dirasa belum sesuai maka sistem akan direvisi kembali ketahap pengujian sistem.

\section{HASIL DAN PEMBAHASAN}

\section{Perancangan}

1. Perancangan Smart Gate

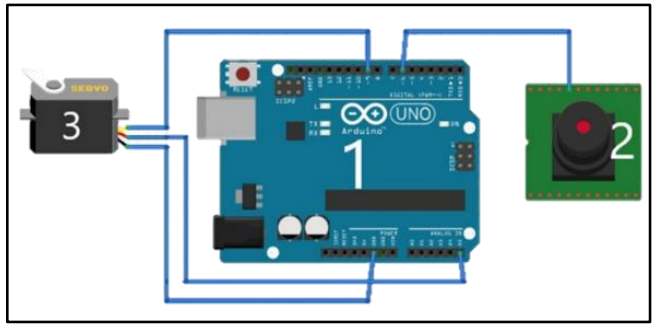

Gambar 2. Perancangan Smart Gate

2. Diagram Alur Sistem

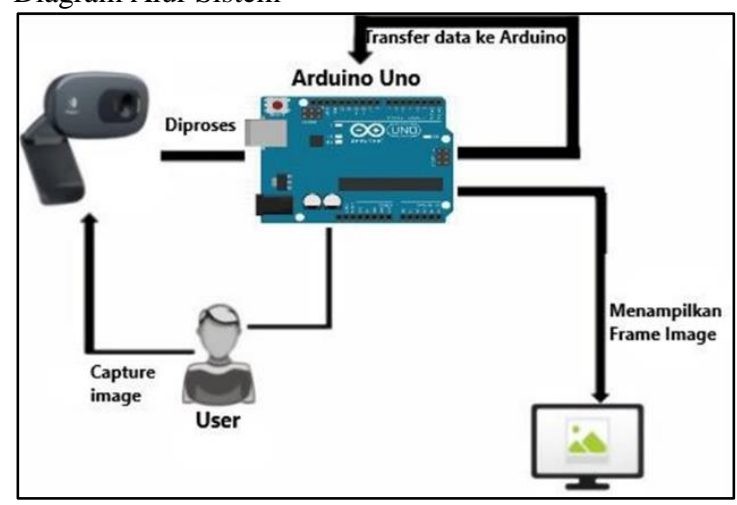

Gambar 3. Diagram Alur Sistem

3. Diagram Blok Sistem

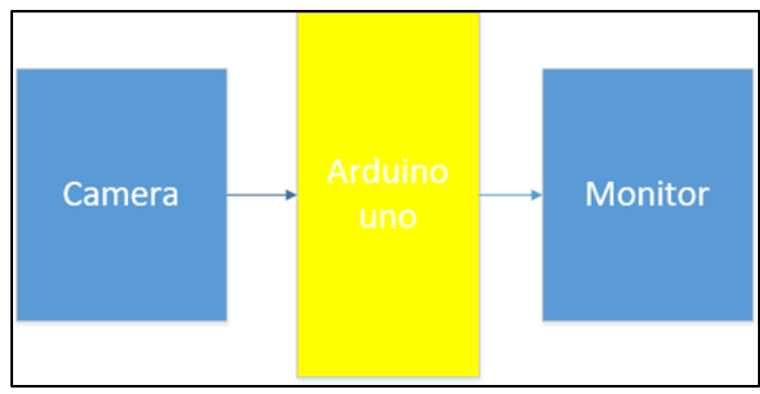

Gambar 4. Diagram Blok sistem

Hasil Implementasi

A. Proses Face Recognition

Setelah persiapan sistem dilakukan, penulis melakukan proses face recognition. Langkah yang dilakukan yaitu:

1. Pengumpulan data dengan melakukan deteksi wajah secara aktual. Untuk mendeteksi citra pada Face Recognition, penulis menggunakan metode Local Binary Pattern Histogram $(L B P H)$ cara untuk deteksi objeknya. Pengumpulan data dapat dilakukan dengan cara melakukan proses deteksi secara berulang sehingga data yang berada didalam folder datasetakan bertambah.Data tersebutlah yang nantinya akan di latih pada tahap selanjutnya. Data yang diambil dapat gunakan sesuai kebutuhan. Semakin banyak dataset yang dihasilkan dalam satu citra wajah, maka semakin mudah dan mempercepat proses pengenalan citra pada saat pendeteksian wajah. 


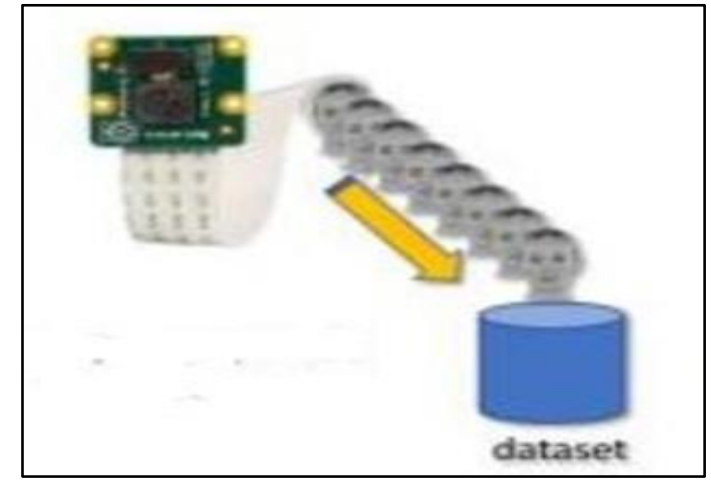

Gambar 5. Dataset

2. Setelah dilakukan pengumpulan data, penulis melakukan pengolahan citra kebentuk binery pada sistem deteksi untuk dapat mengenali wajah

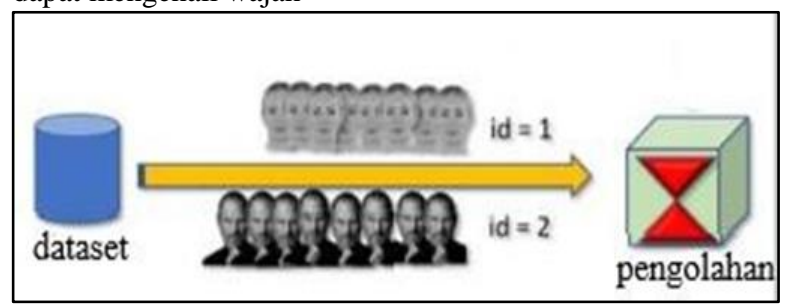

Gambar 6. Proses Pengolahan data

3. Tahap selanjutnya adalah tahap pengenalan wajah. Tahap ini dilakukan jika proses pelatihan telah selesai dilakukan. Karena sebelumnya data hanya dicatat dan disimpan didalam dataset dengan nama folder yang berbeda-beda. Pada saat pelatihan dijalankan dengan menggunakan metode LBPH, maka citra dapat dengan mudah dikenali sebagai identitas masing-masing citra. Sehingga pada saat melakukan Face Recogniton, sistem telah mengenali wajah dari masing-masing citra yang dideteksi

a. Pengujian Alat

Pada proses pengujian peneliti melakukan eksperimen berdasarkan data traning ada dengan mengeluarkan data yang terdapat pada data set. Untuk mengetahui data set yang telah dimasukan tersebut kita memerlukan tools Arduino Uno dan Python. Pada prosesnya yaitu dengan melakukan scan pada wajah lalu melakukan traning data dan lalu menjalankan scan deteksi wajah untuk mengakases ruangan.Hasil dari pengujian berdasarkan scan pada wajah dapat kita lihat pada gambar berikut ini.

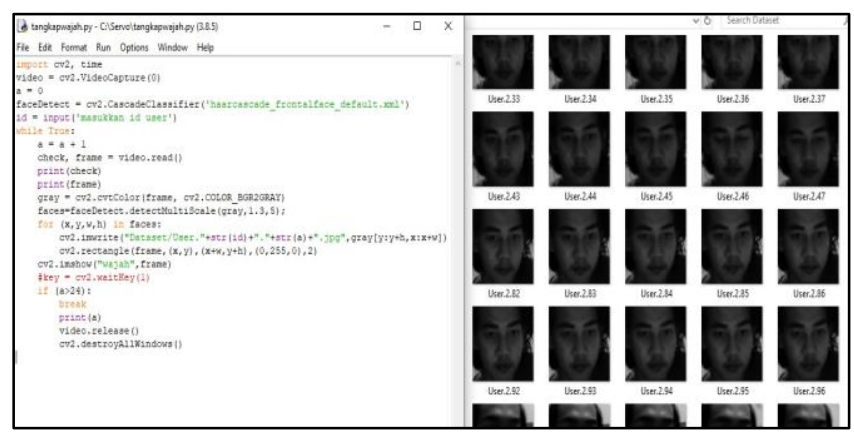

Gambar 7. Proses Memperoleh Data Set

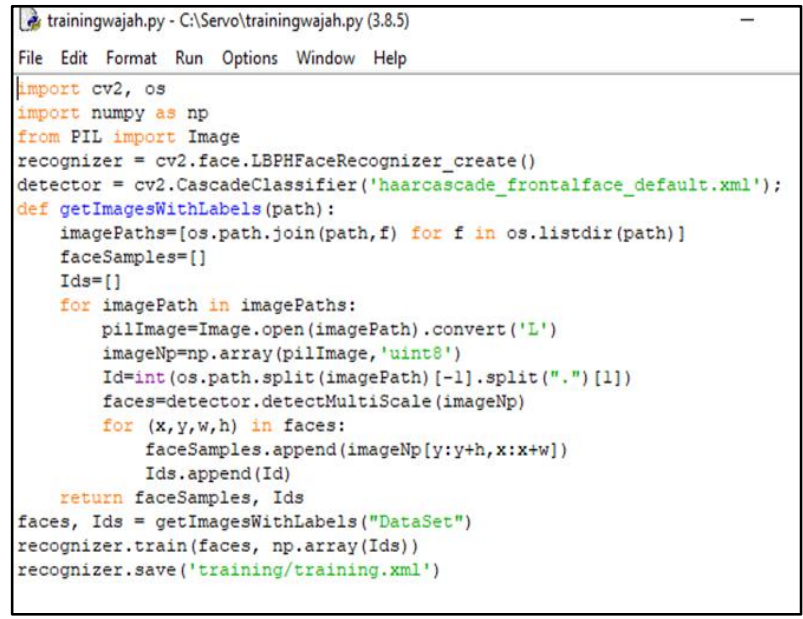

Gambar 8. Proses Tranning Data

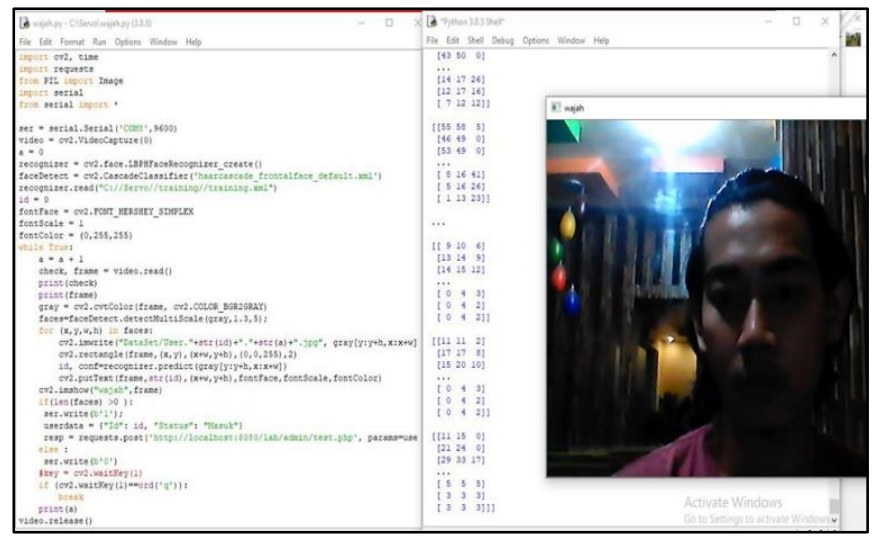

Gambar 9. Proses Face Recognition Untuk Mengakses Ruangan.

b. Pengujian Sistem

Pada tahap ini peneliti akan melakukan pengujian sistem dan alat sehingga peneliti dapat menemukan kekurangan yang terjadi pada sistem dan alat yang sudah dibangun menggunakan Arduino Uno. Pengujian merupakan proses yang dilakukan untuk mencari kesalahan atau error dengan menjalankan program. Program yang dijalankan berdasarkan data hasil deteksi data waja akan dikirim ke database. Data tersebut akan tersimpan didalam database lalu data yang telah disimpan akan di olah dengan metode LBPH menggunakan Python. Berdasarkan hasilpengujian pada proses telah dihasilkan beberapa fungsi diantaranya adalah sebagai berikut :

1) Halaman login

Merupakan halaman yang berfungsi agar admin dapat melakukan login kedalam halaman utama.

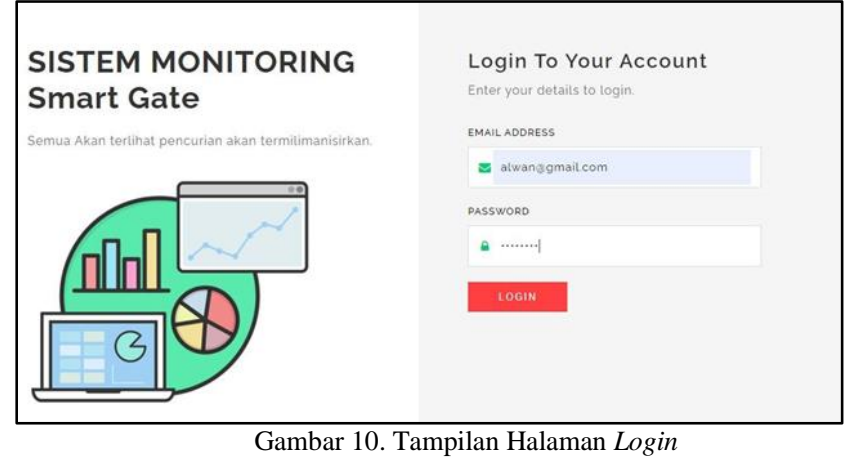


2) Halaman Utama

Merupakan halaman yang berfungsi untuk menampilkan halaman utama admin yang terdapat pada sistem smart gate.

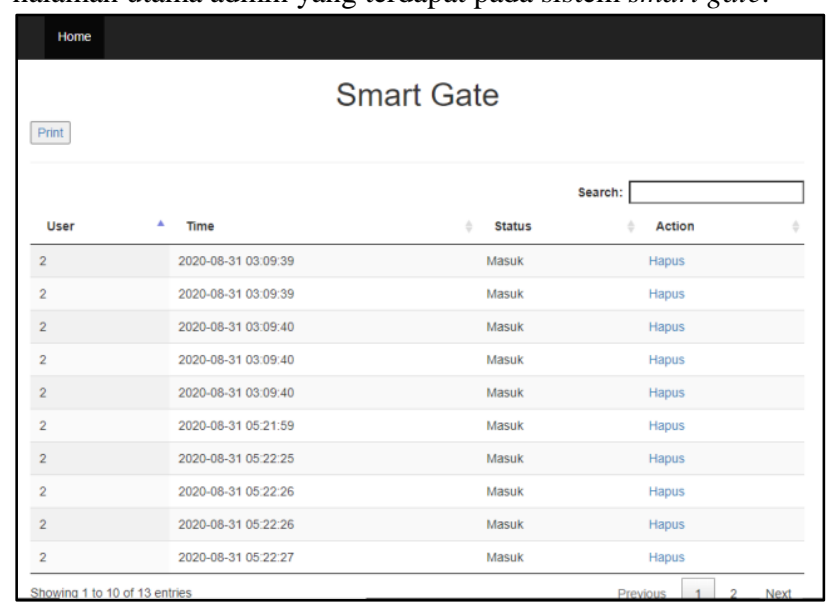

Gambar 11. Tampilan Halaman Utama

3) Halaman Report Data log Pengguna

Merupakan halaman yang berfungsi untuk menampilkan siapa saja yang telah mengakses ruangan menggunakan sistem smart gate lalu di eksport ke PDF.

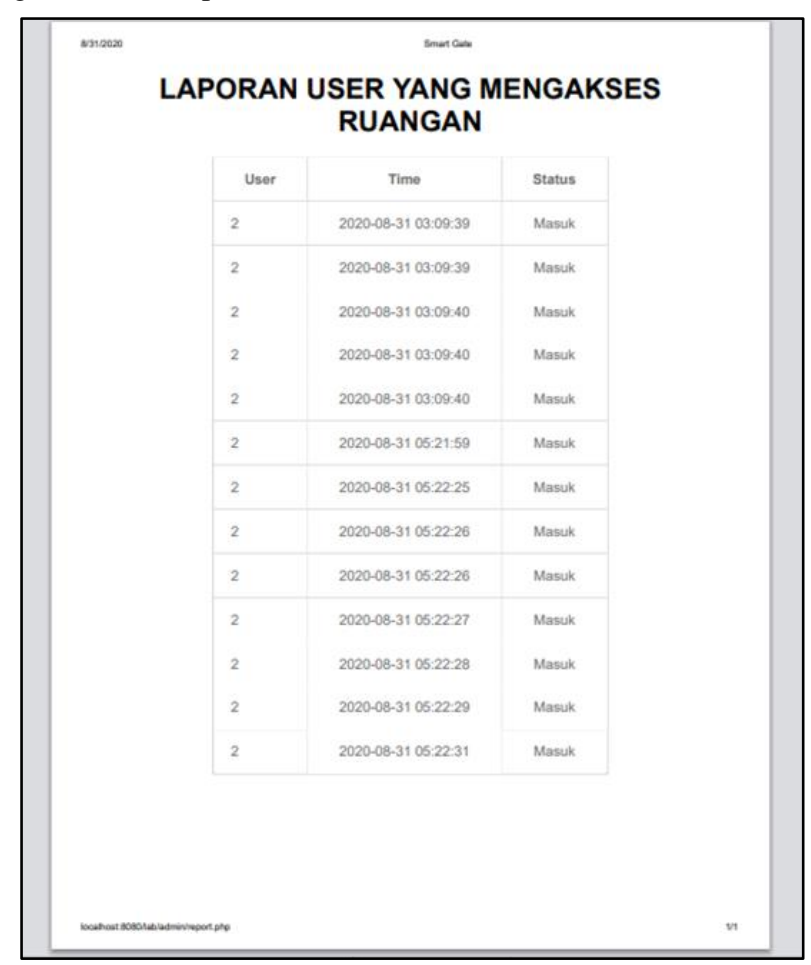

Gambar 12. Tampilan Halaman Report Data Log

c. Hasil

Dari penelitian yang telah dilakukan hasil yang dapat ditunjukan adalah sebagai berikut :

1. Berdasarkan hasil pengujian yang telah dilakukan, penilitian ini telah berhasil menerapkan perancangan sistem keamanan Smart Gate dengan menggunakan mikrokontroler Arduino Uno dengan memanfaatkan Biometric face recognition.

2. Penelitian ini menggunakan Arduino Uno untuk membuat sistem keamanan pintu dengan Biometric face recognition. Data yang diambil berdasarkan data tranning yang telah ditentukan dan dapat dijadikan data sample yang menunjang pada penelitianini.

\section{KESIMPULAN}

Berdasarkan hasil dari penelitian alat yang telah dilakukan, pengujian ini berhasil menerapkan smart gate yang berbasis mikrokontroler Arduino Uno dengan memanfaatkan biometric face recognition.

1. Dapat mengamankan ruangan yang bersifat pribadi/private.

2. Dapat memaksimalkan penggunaan komponen-komponen elektronik agar dapat digunakan sebagai alat yang dapat mengenal karakter wajah agar dapat mengakses ruangan.

3. Dapat mengemplimentasikan algoritma LBPH untuk pengenalan karakter wajah.

\section{DAFTAR PUSTAKA}

[1] Anil K.J., Arun, R., Salil, P. 2004. An Introduction to Biometric Recognition. IEEE Transactions on Circuits and Systems forVideo Technology. Vol. 14(1): 4-20.

[2] Kwok-Wai, W., Kin-Man, L., Wan-Chi, S. 2002. An efficient algorithm for human face detection and facialfeature extraction under different conditions. Pattern recognition. Vol. 34(10): 1993-2004.

[3] Sri karnila, Rio Kurniawan, Sri Lestari, Suhendro Y. Irianto "Aplikasi Pengenalan Wajah Menggunakan Teknik CBIR untuk Objek Tampak Depan” Volume 1, Oktober 2017 ISSN: 2614-1205. 